\title{
Research After the Actual Condition of Fatigue and Accidents due to the Japanese Cultivator
}

\author{
Kazuo SAKamoto, M. D. \\ Chief, Dept. of Surgery, Komoro Branch of Saku Central Hospital, \\ Nagano Pref.
}

First of all, I would like to say about the speciality of Japanese agriculture. -first slide please-

Today, the total population of Japan is over one hundred million, about 30 per cent of it are farmers and their families.

They own individually rather small cultivating land, which consists of paddy fields, vegetable fields, orchard and so on.

Therefore, the scale of the farming remains even now very small, and it is apparent that the great modern farming machines as used in Europe and America are so difficult to be introduced generally in Japan. - next slide please-

But after the World War 11 many kinds of farming machines are being introduced in our agriculture, particulary, various small cultivating machines, named power tiller or tiller type tracter, are going to be used most commonly.

These cultivators with a gasolin engine of from 3 to 9 Horse power can not be ridden at the cultivating work in fields where these are used with plough attached, but can be ridden on road as the carriage.

The district, where our hospital is located, is moderate Japanese farm area at plateau, from six hundred to one thousand and two hundred meters above sealevel, and farmers have rather small arable land from 0.3 to 0.6 hactars of the

Fig. 1 Increase of power tiller in Japan

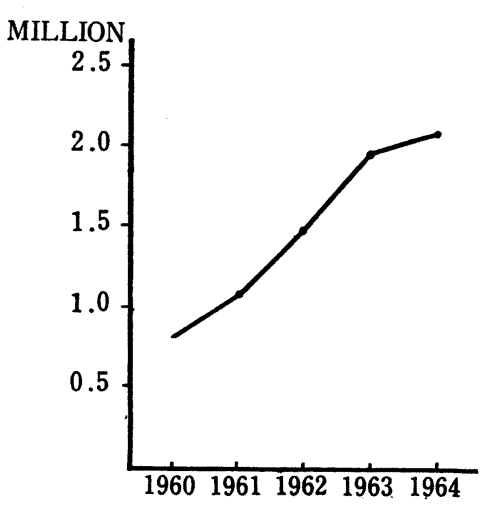

Accidents caused by power tiller (Out-patients of Saku C.H.)

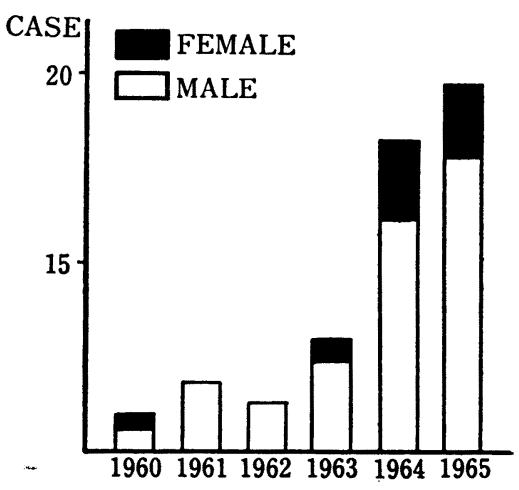


paddy field and about same hactars of some other field. Each field scarcely extends over 0.1 hactar.

And now number of power tillers introduced are increasing also in our district so rapidly.

Consequently, accidents caused by them are increasing since 1963, and moreover it is important that even women are meeting with these accidents recently. (Fig. 1)

These accidents occur during cultivating work or removing or transportation on farm path and on road for carriage, because of the unadequate facilities of the machine and lack of experience of farmers.

Under such a fact we carried out the investigation on the physiological work loads of farmers, using the power tiller.

These cultivating works, that are the coarse ploughing and the puddling after flowing water in the field, are performed before the rice-transplantation.

According to the time study of farmer's daily life actual ploughing time with power tiller is in average about from 5 to 6 hours a day. (Fig. 2)

Fig. 2.

TIME STUDIES ON FARMER'S DAILY

LIFE IN BUSY SEASON

( WORK IN PADDY FIELD)

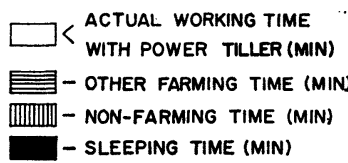

A) AT THE SEASON OF COARSE PLOUGHING

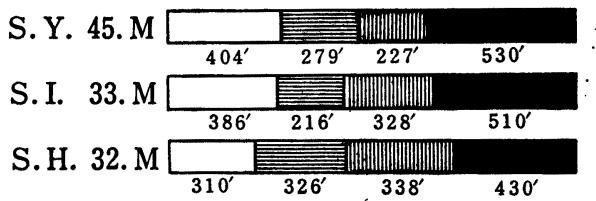

B) AT THE SEASON OF PUDDLING

\begin{tabular}{|c|c|c|c|}
\hline \multirow{2}{*}{ C. S. $49 . \mathrm{M}$} & & = & \\
\hline & $326^{\prime}$ & $237^{\prime}$ & 37 \\
\hline Y.S. 42.M & & 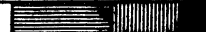 & \\
\hline & $364^{\prime}$ & $351^{\prime}$ & 480 \\
\hline T.S. $40 . \mathrm{M}$ & & 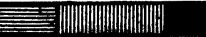 & \\
\hline
\end{tabular}

The ploughing by power tiller attached with single plough has some differences to that attached with rotary plough.

The former is more quicker in speed than the latter, but the cultivating efficiency is not so different, because the width of ploughing is more narrower in the former than in the latter. 
In the ploughing work the farmer must walk with speed of 50 or $60 \mathrm{~m}$ per minute in the case of single plough and 25 or $39 \mathrm{~m}$ per minute in that of rotary plough. The puddling is made in the speed of 45 or $55 \mathrm{~m}$ per minute with the attached harrow in the water filled paddy field.

The amount of the energic consumption of farmers doing these works depends. on mainly their walking speed and the condition of field. In Japan R. M. R. (Relative Metabolic Rate) is widely used as an index to the magnitude of the energic consumption for muscular work, which is appreciated as a good indicator for the intensity of work, without regarding the variation of individual basal. metabolic rate.

According to our present research, each R. M. R. was from 3.0 to 3.5 at single plough, from 2.0 to 2.8 at rotary plough, and that of puddling was from 4.0 to 5.0 . (Table 1).

Table 1. R. M. R. of Ploughing and Puddling Work with Power Tiller

\begin{tabular}{|c|c|c|c|c|c|c|c|c|c|}
\hline \multirow[b]{3}{*}{ U.K. 26. M } & \multirow{3}{*}{$\begin{array}{c}\text { Height } \\
\begin{array}{c}\text { C.M. } \\
157\end{array}\end{array}$} & \multirow{3}{*}{\begin{tabular}{|c|} 
Weight \\
$\begin{array}{c}\text { K.G. } \\
55\end{array}$
\end{tabular}} & \multirow{3}{*}{$\begin{array}{c}\begin{array}{c}\text { Body } \\
\text { Surface }\end{array} \\
\mathrm{M}^{2} \\
1.56\end{array}$} & \multirow{3}{*}{$\begin{array}{c}\text { B.M.R. } \\
\begin{array}{c}\mathrm{O}_{2} \text { C.C. } \\
\text { /MIN }\end{array} \\
\begin{array}{c}\text { C.C. } \\
193\end{array}\end{array}$} & \multicolumn{4}{|c|}{ R. M. R. } & \multirow{3}{*}{$\begin{array}{l}\begin{array}{l}\text { Used } \\
\text { Power } \\
\text { Tiller }\end{array} \\
6 \mathrm{HP}\end{array}$} \\
\hline & & & & & \multicolumn{2}{|c|}{ Coarse Ploughing } & \multicolumn{2}{|c|}{ Puddling } & \\
\hline & & & & & 3.3 & $\mid$\begin{tabular}{c|} 
S.P. \\
SP. $45 \mathrm{M}$ \\
$/ \mathrm{MIN}$
\end{tabular} & 5.7 & 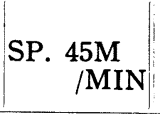 & \\
\hline T.S. 39. M & 162 & 44 & 1.49 & 175 & 3.4 & $\left|\begin{array}{c}\text { S.P. } \\
\text { SP. 40M } \\
\text { /MIN }\end{array}\right|$ & 5.0 & SP. $40 \mathrm{M}$ & $4 \mathrm{HP}$ \\
\hline K.S. 45. M & 159 & 55 & 1.50 & 189 & 2.8 & $\mid \begin{array}{c}\text { S.P. } \\
\text { SP. } 25 \mathrm{M} \\
\text { /MIN }\end{array}$ & 4.3 & $\mid \begin{array}{c}\text { SP. } \\
\text { /MIN }\end{array}$ & $6 \mathrm{HP}$ \\
\hline C.S. 53. M & 162 & 63 & 1.68 & 208 & 2.3 & $\left|\begin{array}{c}\text { R.P. } \\
\text { SP. } 25 \mathrm{M} \\
\text { /MIN }\end{array}\right|$ & 4.8 & 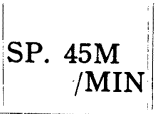 & $6 \mathrm{HP}$ \\
\hline
\end{tabular}

S.P. Single Plough

R.P. Rotary Plough

S.P. Speed

These R. M. R. are respectively above leveled in comparison with R. M. R. of free walking as the figure (Fig. 3) shows.

Their caloric consumption per day in this work season are in average about. two thousand Cal. for only cultivating by power tiller, about two thousand and three hundred Cal. including other farm work, and then about three thousand and three hundred Cal. in total (Table 2).

As has been previously mentioned, the power tiller are used not only for cultivating, but for the carriage, because they are so effective to ride on narrow farm path and relieved the farmer's burden by the primitive carriage.

We, however, should consider that their health could be influenced by the severe vibration of the machine, because this is not devised so adequately for riding and 
Fig. 3. R. M. R. Compared With walk Speed

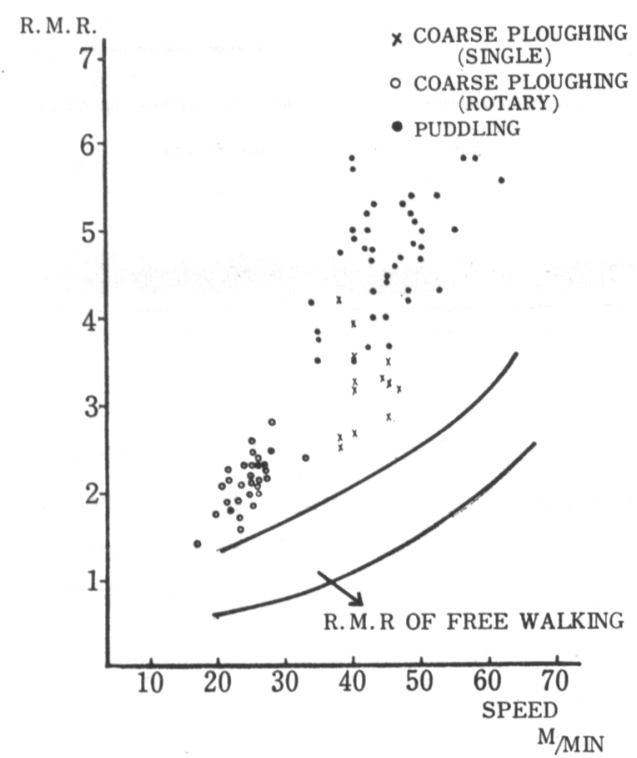

Table 2. Caloric Consumption During Coarse Ploughing and Puddling

\begin{tabular}{|c|c|c|c|c|c|c|}
\hline & & \multicolumn{3}{|c|}{ Farming Work } & \multirow{2}{*}{$\begin{array}{r}\text { Total Caloric } \\
\text { Consumption } \\
\qquad / 24 \mathrm{H}\end{array}$} & \multirow{2}{*}{$\begin{array}{l}\text { Used } \\
\text { Machine }\end{array}$} \\
\hline & & $\begin{array}{l}\text { With Power } \\
\text { Tiller }\end{array}$ & $\begin{array}{l}\text { Without } \\
\text { Power Tiller }\end{array}$ & Total & & \\
\hline \multirow{4}{*}{$\begin{array}{c}\text { Coarse } \\
\text { Ploughing }\end{array}$} & K.S. $45 . \mathrm{M}$ & $\begin{array}{l}\text { CAL } \\
1816\end{array}$ & $229^{\text {CAL }}$ & $\begin{array}{l}\text { CAL } \\
2045\end{array}$ & ${ }_{2936}^{\text {CAL }}$ & Single Plough \\
\hline & Y.S. $42 . \mathrm{M}$ & 2019 & 399 & 2358 & 3157 & " \\
\hline & T.S. $53 . \mathrm{M}$ & 2086 & 299 & 2385 & 3334 & Rotary Plough \\
\hline & I. S. $41 . \mathrm{M}$ & 1683 & 113 & 1796 & 2689 & " \\
\hline \multirow{2}{*}{ Puddling } & C. S. $53 . \mathrm{M}$ & 2087 & 212 & 2309 & 2468 & \\
\hline & Y.S. $42 . \mathrm{M}$ & 2166 & 630 & 2796 & 3645 & \\
\hline
\end{tabular}

many farm paths are very bad. The speed of the power tiller is from 10 to $15 \mathrm{~km}$ per hour on a plain road and from 5 to $10 \mathrm{~km}$ per hour on a slope of bad farm path,

In this case the polygram indicated the frequent alternations of nervous or functional tension, shown in the heart rate, respiratory rate, galvanic skin reflex and electromyogram, that were caused by the badness of path, turning and difficulties of driving. (Fig. 4) 
Fig. 4. T. S. 43.M Polygraph during the use of Power Tiller as Carriage

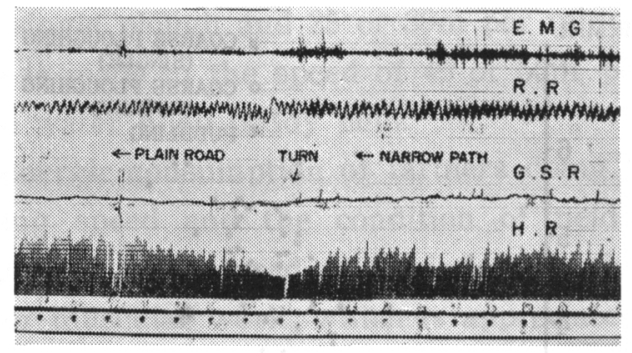

These R.M.R. of carriage is varied from 0.2 to 1.5 according to road condition. Subsequently, the variation of flicker fusion frequency as a fatigue test in the daily cultivating work did not show cinsiderable decrease, but it seemed to be noteworthy that the lassitude, shoulder stiffness and dullness of the extremities were highly complained as subjective symptomes. (Fig. 5)

Fig. 5. Complainments of Fatigue by the Use of Power Tiller

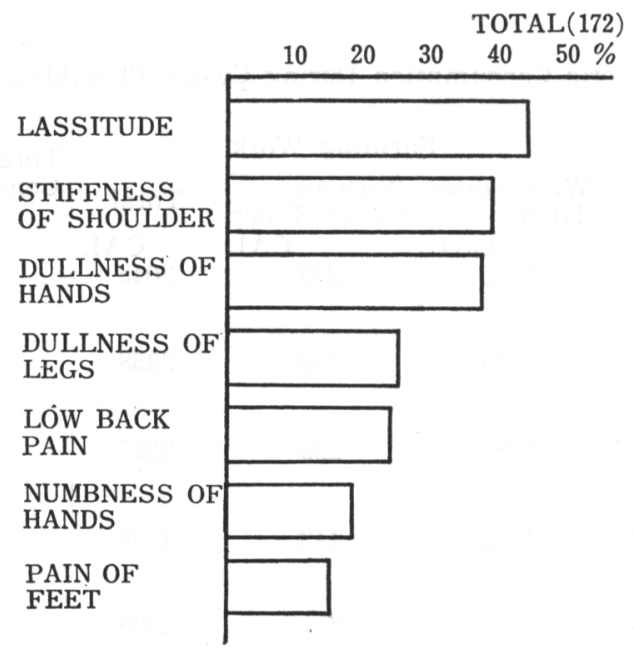

The speaker reported on remarkable increase of characteristic power tiller in Japanese agriculture, the present state of accidents caused by them and physiological work loads and fatigue of the farmer under working with them. The mechanization in agriculture will develop much more, even in Japan in order to lighten the bodily burden and to level up the farming efficiency. It is essential that this mechanization should be considered to be fit to the farmers health and life ergonomically and socially. 